\title{
Aura, Aurora and Aurality: \\ The Narrative of Place in Picture of Light
}

\begin{abstract}
Peter Mettler's Picture of Light (1994) is a self-reflexive study of media, knowledge and nature - how we understand and come to know the world through film and photography. My analysis draws on haptic theory, sound studies and Pierre Bourdieu's notion of the habitus to look at the permeable boundaries between the subject and audience, image and sound, and immersion and reflexivity. In this paper I use different interpretations of scripts and improvisation to look at how narrative, technique and technology can all be traced to the placement of the body in space and time and how these themes are used in the film to create an experience that, somewhat in opposition to what appears as the narrator's emphasis on distancing, creates an aura of the attempt to represent the Aurora Borealis on film.
\end{abstract}

Key words

Phenomenology; haptics, habitus; aura; sound studies

North is where all the parallels [similitudes as well as longitudes] converge to open out ... into the mystery surrounding us.

(Grace 2002)

The north focuses our anxieties. Turning to face north, face the north, we enter our own unconscious. Always, in retrospect, the journey north has the quality of dream.

(Atwood 1987) 


\section{Introduction}

While contemplating the significance of the Northern Lights in Picture of Light (1994), director Peter Mettler explains how they have been described as "visions, prophecies, spirits, a trigger of the imagination". Through this phrase he establishes a correlation between the experience of the lights in person and the experience of mediation. By pulling the audience into uncertainty over whether the images are authentic, Mettler is able to challenge what constitutes experience and knowledge in a highly mediated world. Steven Shaviro (1993) wrote, "[c]inema is at once a form of perception and a material perceived, a new way of encountering reality and a part of reality thereby perceived for the first time" (1993: 41). Cinema, then, is both an indexical object referring to the original experience and an object in the present. By providing the audience with space to navigate through reflexive filmmaking, I propose that Picture of Light intentionally provides opportunity for methodological insight towards a more nuanced understanding of film and our relation to knowledge and to the natural world through mediation.

Through the use of haptic theory, sound studies and Pierre Bourdieu's notion of the habitus, this paper will take a phenomenological standpoint to explore the permeable boundaries that make Picture of Light successful in scrutinizing the boundaries of cinematic representation. I will employ interpretations of scripts and improvisation to explore how narrative, technique and technology can all be traced to the placement of the body in space over time and how these themes are used in the film to create an experience that, somewhat in opposition to what appears as the narrator's emphasis on distancing, creates an aura of the attempt to represent the Aurora Borealis on film. The aim of this paper is to demonstrate that through the intentionally ambiguous nature of representation and experience, Picture of Light is able to transcend the limits of representation and create a dynamic space that allows for a participative mode of spectatorship.

\section{Silent Light}

A common theme in Mettler's work is "a sense of wonder," trying to represent the unrepresentable. ${ }^{1}$ He cites the Japanese word yugen, "an awareness to the universe that triggers feelings too deep and mysterious for words", as a philosophical underpinning to his approach (Mettler 1992: 41). Throughout this paper I will argue that Mettler is most deliberate in the creation of in-between spaces and that it is a result of the ambiguity of place that the film is most successful.

Mettler has written about the influence of music on the arrangement of his films, the use of musical techniques for the structuring of images. ${ }^{2}$ It is not the "added value" of the music guiding the images through the use of a score, but rather that images can be presented in a way that operate in an abstract manner, similar to music. ${ }^{3}$ A similar approach can be seen in his use of location sound, as recordings are often processed so they blur with the soundtrack, confusing the 
reference to develop the ambiguous nature of the film. Processes such as these are used so that their reference is often obscured; essentially oscillating between affect and account. In other words, the film shifts between reflexive and observational modes of documentation.

The film opens in an industrial freezer with the crew testing out their recording equipment for Arctic conditions. The ominous drone of the refrigeration masks all subtle sounds. A shotgun microphone attached to a boom pole is visible, its location and movement is emphasized through the soundtrack. As Mettler asks Andreas Züst, the film's producer, to explain where they are his voice is highly reverberant, echoing off the flat metallic walls of the storage unit. However, as Mettler asks a second question the microphone is directed toward him; his voice becomes more pronounced and clear, telling less of the physical environment and more of the effects of the recording equipment. Whether this was intentional or not it places Mettler as both a subject within the film and as an observer removed.

The following scene is a montage of the train journey north to Churchill, Manitoba. Scenes of the crew recording video and audio of the train and passing landscape are seen and heard while Mettler, his voice meditative and rhythmic, states:

Film. Media. With its potential to commodify, turn into commodity anything that is meaningful to us - business and numbers out of life force and wonder. Maybe this wacky process of harnessing money and technology is just an

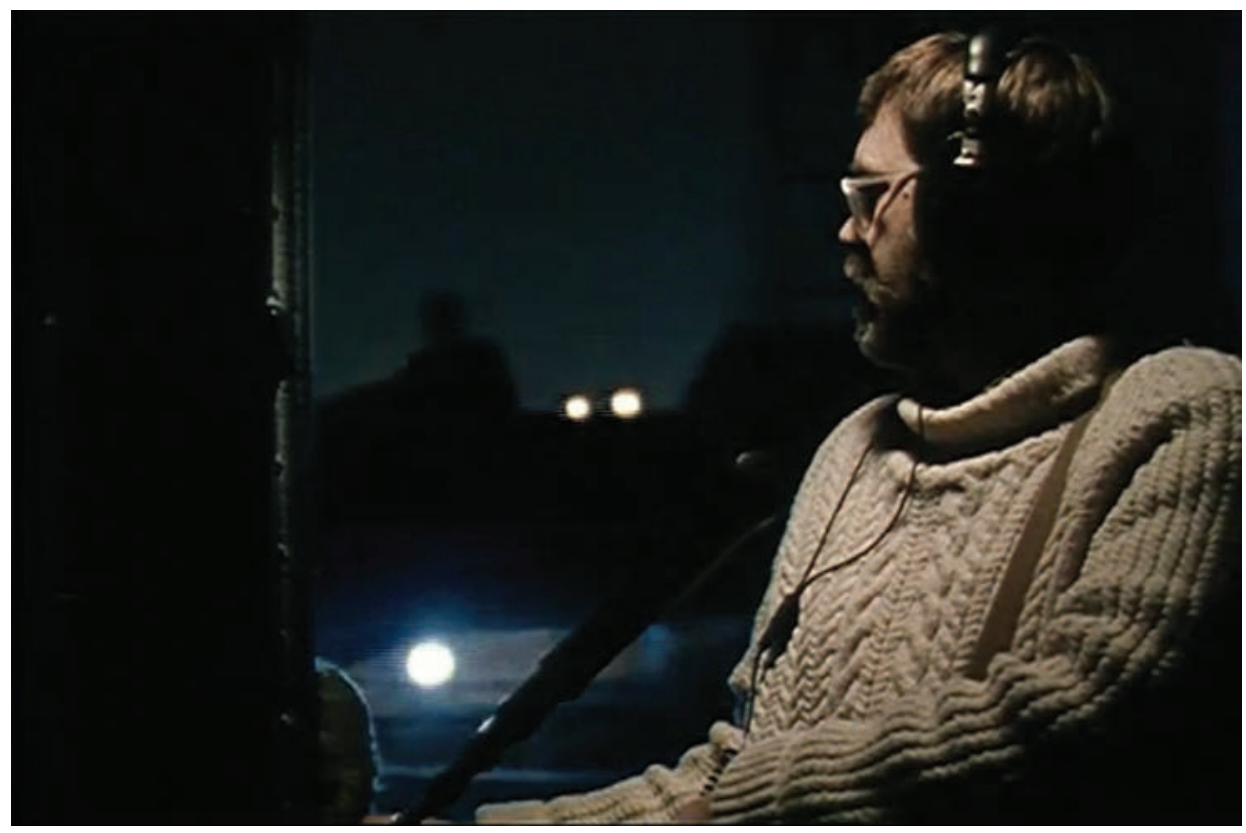

Figure 1. Is it the sound of the train or part of the film's score? By highlighting the recording process Mettler continually challenges the audience's relationship to the film. 
extension of thinking, of trying to understand. These images and sounds are articulations of experience. We look at them and try to decipher the reality that gave birth to them.

Throughout this sequence sounds fade in and out of synchronization with the images. Extending their ambiguous referentiality they are processed to blur with the score. Subtle use of feedback and resonance blur the sounds of the train, creating both questions about and potentials for the soundtrack's origins. ${ }^{4}$

The processing of the film's sound early in the film indicates Mettler is not concerned with notions of fidelity, of being truthful to points of origin. It is in these processes that we can uncover the playful value of authenticity as well (the most challenging aspect when interpreting aura). In The Malaise of Modernity (1991) Charles Taylor claims that the concept of authenticity can be traced to the late eighteenth century as "human beings [were] endowed with a moral sense, an intuitive feeling of right or wrong" (1991: 27). This moral sense, Taylor suggests, connects the actions of an individual to their "feelings" and it is this relationship that constitutes a "certain way of being human that is $m y$ way" (1991: 29; original emphasis). In Western tradition, for one to be authentic means to be true to one's self. Authenticity has since been adapted to culture and art; to be an authentic artist one must be connected to origins, likewise for piece of art to be authentic it must be made by an authentic artist in a specific time and place. The assertion that one thing is authentic while another is not becomes a challenge as authenticity is context dependent. So, as the sound in the early scenes in the film indicates, Picture of Light is not an attempt to represent the original experience of the Northern Lights on film but rather highlights the process of its origin in an attempt to reconcile the limitations of reproduction in order to achieve authenticity on another level - i.e. yugen.

Elsewhere in the film time-lapse shots provide renditions of the Northern Lights while the voice-over describes the technical process that made the images possible. The result of the camera is emphasized throughout these scenes as the angle is sporadically adjusted, abruptly altering the horizon. These scenes are reminiscent of the work of Stan Brakhage and situate the audience in relation to the film as an object rather than index. ${ }^{5}$ While Mettler's onscreen dialogue informs the audience of the processes involved in the rendering of these images, he encourages the audience to interpret the film through an awareness to how mediation works.

During these scenes, as the lights dance across the screen, Mettler makes no attempt to represent the sounds they make. He describes it as something of a static discharge, "as though your head ... acted like a conductor to the currents in the night sky." But still, the lights remain silent. The use of conductor in this line is very interesting, it can refer to both an electrical conductor in which the individual's physical body facilitates the electric charges or a musical conductor as someone who directs a musical performance, in this case the performance of the silent lights. 
Randolph Jordan (2010) proposes that Mettler's claim that the lights move "like thoughts" creates, for the audience, "an external manifestation of an internal experience" (2010: 189). Suggesting a negation of space, the audience's imagination and the Northern Lights merge, as if the viewer were conducting the pattern of the lights themselves. Jordan uses this idea of haptic space as a way "to move past critiques of documentary veracity" to recognize the potential of the film in transcending "the boundary between subject, film, and audience" (2010: 189). He argues that Mettler's recognition of the manufactured nature of film, both sound and image, allow the director to bypass notions of fidelity (and by extension authenticity) to use the representation to create a unique experience for each audience member. Jordan suggests that " $[\mathrm{t}] \mathrm{h}$ e experience of the northern lights in this film, while at an aesthetic remove from the real thing, can trigger the mind in a way that is no different from being there in person" (2010: 189). The Northern Lights do not transcend the mediating technologies in Picture of Light. Rather, Mettler creates a space that allows the audience to engage with the film on their own accord, as an object in the world.

What Jordan ultimately argues is that Mettler intentionally exploits the division between sound and image to highlight the constructed nature of film. This is not an attempt to discredit the medium, but highlights how it impacts upon our interpretation of the represented. The silence of the lights encourages an awareness to the uniqueness of the film, from the technologies used to the techniques practiced, and attempts to communicate the experience of wonder by allowing each audience member to imagine their own.

\section{Framing Presence}

As Picture of Light is about both the filmmaker's experience and the audience's understanding of the world, the use of television sets to frame moments referencing reality outside of the film is particularly apt. The voice-over states: "We live in a time where things do not seem to exist if they are not contained as an image." If we replace the word 'image' with 'story', we can adapt this question to our understanding of history; what do we know of the past that is not contained in a story, whether a story spoken or written, or a story constructed from scientific analysis of physical objects? How do we relate to these stories even though most of us will never experience such an event in person? In this section I will cover the various roles mediation play in the film's construction, including the use of pre-existing footage from NASA. A connection will be established between the content and the devices used in the making of the footage. To do so I will build on Jonathan Sterne's adoption of Bourdieu's concept of the habitus, to make a connection between technology and the body.

Within the film's mise-en-scène, images appear on the television recorded by the crew (referencing the construction of the film), by the hotel manager (referencing a time beyond the scope of the filming) and finally being broadcast by a local cable 


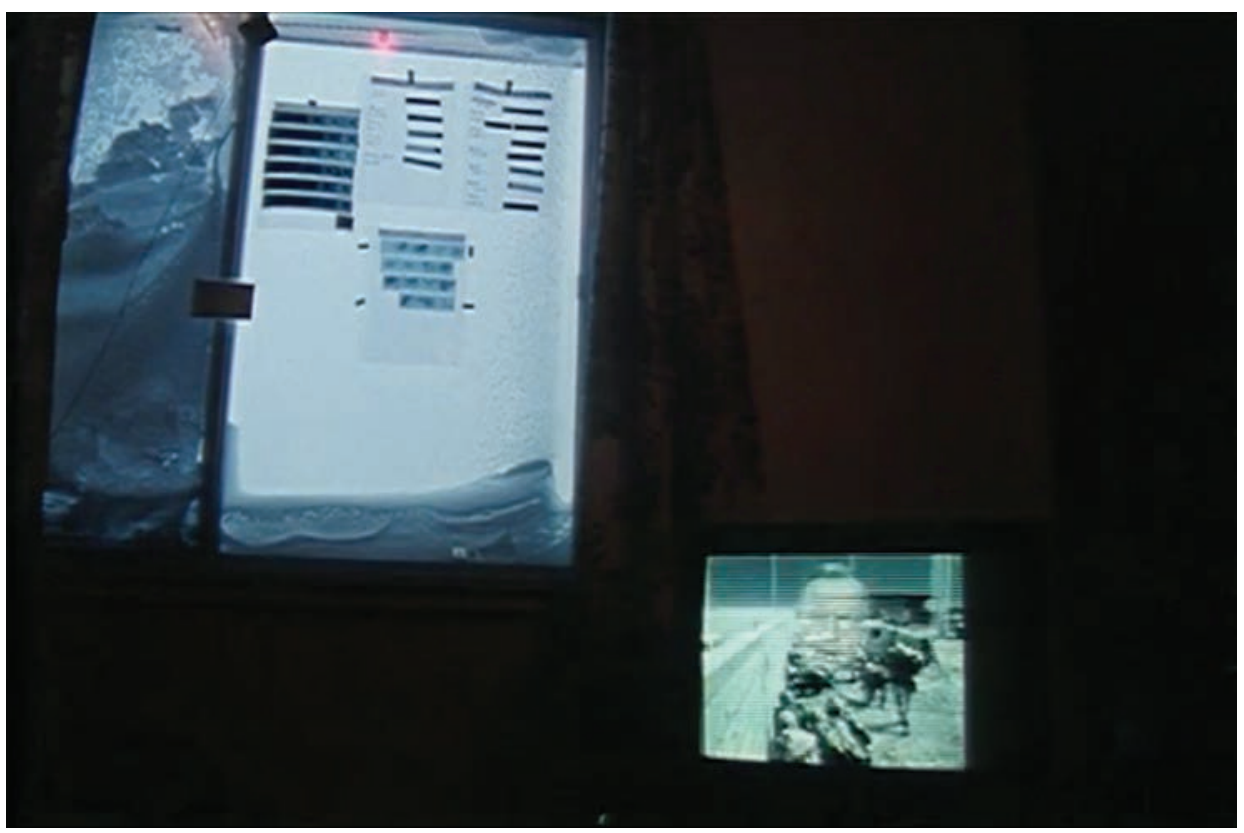

Figure 2. A window of windows.

station, from text based news and weather to sports highlights to George Bush Sr.'s image floating on the screen as the news reporter tells of "Iraq's" taunting of allied forces (highlighting the role of technology in connecting all members of a mediated society). While the latter is most familiar to the film's audience, within the context of Picture of Light it is the most foreign, even as Mettler attempts to acclimatize it by stating: "TVs run in every room. The screens keep us informed about the conditions outside. It's as though we are distracted from knowledge by learning." This statement seems to challenge the value of information in a highly mediated environment (albeit a primitive one by today's standards). This is both a challenge to the filmmaker's value and raises questions about the audience's understanding of the world and the role of mediation in knowledge and learning. Furthermore, it raises the notion of context within a culture of recombination.

Walter Benjamin (1983) wrote: "To write history ... means to quote history. But the concept of quotation implies that any given historical object must be ripped out of its context" (1983: 49). A citation could be, among other things, embedded in text, a sample in a song, or in the case of Picture of Light, framed by a television screen. Quotation adds a layer of remove. The new question becomes what does the new context tell? By looking at a sequence of images of the Northern Lights shot from below, by Mettler and his crew, and from above, from the NASA space station 190 miles above sea level, the audience is asked to make the connection that these recordings belong to the same story. 
Footage onboard the Orbiter Challenger shows Doctor Don Lind explaining the significance of the Auroras to life on Earth. These scenes are connected to a montage towards the end of the film where footage of a shuttle launch and a train journey are juxtaposed. The sequence suggests the recordings by Mettler are just another addition to the externalized memory of our mediated world, and that it is only through this construction they take shape of a particular narrative. Relating to the political implications of montage (though he refers to it as collage), William C. Wees (1993) writes:

At the very least, I think it is tenable to argue that collage politicizes art by confronting the viewer with actual pieces of reality within a "frame" that has traditionally signified the separation of art and reality, aesthetic immanence and life praxis. The presence of mass produced objects and images in the previously privileged realm of unique artistic representation not only challenges the autonomy of art (much as mechanical reproduction challenged the "aura" and "cult value" of original works of art), it also offers artists a new way of placing all images - whatever their original source and function - on the same plane of visual expression and subjecting them to the same level of critical analysis. (Wees 1993: 51-52)

By using archival footage the audience is not only asked to think of a connection to the other materials in the film, but also challenges its significance, its meaning, and its relation to the viewer. How much of our knowledge of the Northern Lights was informed by other forms of media?

As well as the political implications of using archival footage, its inclusion as part of collective memory raises the idea of media as being an evolutionary trait of human action. When Mettler states, "[m]aybe this wacky process of harnessing money and technology is just an extension of thinking, of trying to understand," he is discussing the crystallization of consciousness into physical objects. While technology is a fundamental element in the construction of Picture of Light, technique is equally important. Our techniques influence us just as our technologies do, just as both inform us about our understanding of our presence in the world.

While Bourdieu never explicitly wrote on the concept of technology, Sterne (2003b) has adapted many of the sociologist's ideas to explore the relationship of technique and technology. Fundamental to this reading is the concept of the habitus. Essentially, the habitus is a notion of conventions, it "attempts to explain how apparently spontaneous action is rooted in learned, embodied social tendencies" (Sterne 2006: 94) and is governed by what Bourdieu (1990) refers to as "the nonspontaneous principle of spontaneity" (1990: 56). "The way a person walks, talks, types, plays a musical instrument, drives, her aesthetic preferences, perceived health needs, etc., all of these attitudes are expressions of habitus" (Sterne 2003b: 375). In other words, the prevalent actions of everyday life are learned, consciously or not, from our cultural milieu and become an internalized set of patterns of thought and behaviour. Bourdieu has referred to this as 'practical knowledge.' 
Sterne (2003b) suggests that all technologies, no matter how complex, can be traced to human action, as "visible sets of crystallized subsets of practices, positions and dispositions in the habitus" (2003b: 386). This echoes Marshall McLuhan's notion that technologies function as extensions of human perception, ${ }^{6}$ and has been further developed in the work of Friedrich Kittler (1999) who wrote: "[p]sychotechnology relays psychology and media technology under the pretext that each psychic apparatus is also a technological one, and vice-versa" (1999: 160). All technology, no matter how complex, can have its origins traced to human action in space. This understanding helps alleviate assumptions that the use of technology results in the production of inauthentic art, ${ }^{7}$ which is often a concern when issues of the aura arise.

In the context of a film such as Picture of Light it is easy to see how the use of technology is related to the sensory functions of the body, and by extension human action. The camera lens extends our ability to see beyond the limits of time and space, albeit from a limited perspective. I propose that Mettler's approach allows the audience to participate in the construction of the film as they bring their own unique notions of the Northern Lights and cinema into dialogue with the images and sounds. The permeable space of the film is opened up by Mettler's treatment of the lights (slowing and silencing), which foregrounds the function of the technology in mediation, emphasizing the viewer's relationship to the film as both reference and object. While conventions often limit possibilities by favoring recognized or organized behaviour, Mettler's deliberate manipulation of such practices offers the audience a chance to question what the images and sounds represent, what they think they meant at the time referenced and what they feel they mean in the present.

As Picture of Light is a film about knowledge in a mediated world, an emphasis on the role of technology is imperative. So far, I have tried to demonstrate the relation of the body to the use of technology through the manipulation of conventions. In the following section I will extend this thought to the presentation of technology as social actor to demonstrate how Mettler's inclusion of the recording technology creates the aura of the attempt to represent the Northern Lights.

\section{Technological Actors}

As I have already suggested, Picture of Light is a self-reflexive study of nature and technology, and as such aims to reconcile the often assumed division between the two. In this regard, the film attempts, consciously or not, to address Benjamin's "dream of a better nature" (1999: 362), the interrelation between nature and technology (equating the diminution of the aura due to their division). In this section I will address Benjamin's notion of the aura to demonstrate how Mettler's foregrounding of technology serves to create a point of rupture for the audience, to jar one out of one's normal state to foster a new possibility of experiencing the film, and to a much larger extent to one's relationship with world as a whole. 
I suggest that the film is constructed such that the recording devices function as actors within the story. Their characteristics are foregrounded to bring awareness to their contributions. For example, there are many instances where the microphone boom is visible and the audience is able to correlate the movement to the audio signal. These processes of including the recording technology, through reflexive technique and critique, provide the audience with a place to navigate, emphasizing awareness of perspective within the film. As the technologies are related to the body as crystalized social actions, Picture of Light is a study of the habitus of a mediated culture through an exploration and exploitation of conventions.
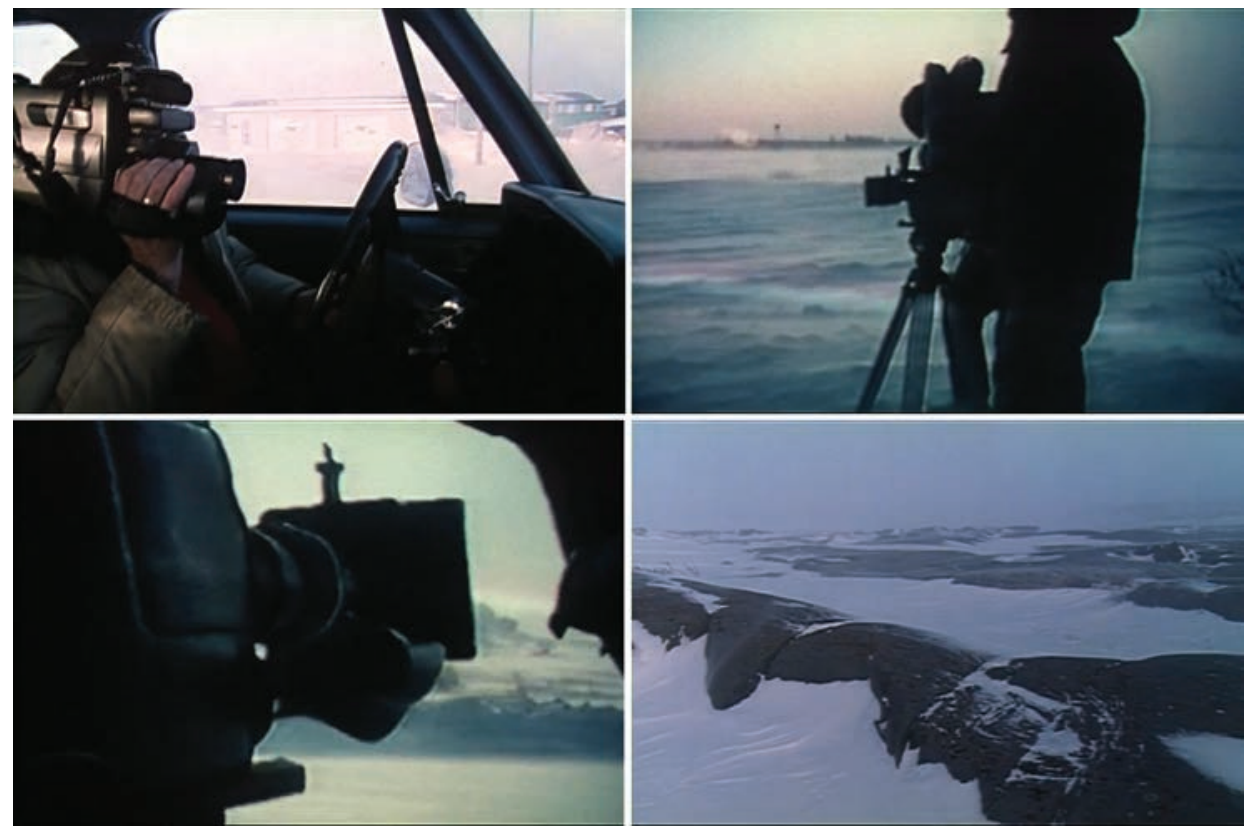

Figure 3. A sequential journey exploring the effects of mediation.

Towards the end of the film Mettler, a crew member and the manager of the hotel drive to the open tundra to record a sunset. Earlier in the film the manager had shown the crew videos of parties he had recorded on his own video camera. The same camera is seen in the hand of the manager as he awkwardly operates the camera and truck at the same time. The sequence of the journey cuts to footage captured on the video camera and back to the film camera. The video footage is emphasized because it was captured by the film camera while being played back on a television screen, the effect of recording different frames rates resulting in the ascending white lines. The most striking part of this scene, however, is the sound of the wind as recorded on both systems. The key point here is that wind 
on its own does not produce sound. It is only when it comes into contact with an object that sound results. The part of the film that was recorded on the video camera is loud and distorted because there is no isolating material on the built in microphone. The footage recorded on the professional film camera was recorded with a properly isolated shotgun microphone and was able to capture the sound of the wind blowing across the tundra. This is significant because the sound of the wind on the microphone only happens while the equipment is there, whereas the second scene captures an impression of the space in a manner that appears to be more transparent. ${ }^{8}$ This serves to disassociate the audience from the fluid footage that makes up a majority of the film (and to a further extent makes one aware of the perception through our own sensory organs). What, then, is the function of distance in a mediated world?

In his seminal paper, "The Work of Art in the Age of Mechanical Reproduction" (1936; 1968), Walter Benjamin wrote about the perceived loss of aura through the mass production of artworks. While the conventional reading of this essay equates the aura with quasi-religious, or occult, value resulting from its physical uniqueness, I will employ a more nuanced reading for the concept. To do so I rely on the essay Benjamin's Aura (2008) by Miriam Hansen. In the article, Hansen provides an extensive survey of Benjamin's many uses of the noun to suggest "it is not an inherent property of persons or objects but pertains to the medium of perception" (2008: 342; original emphasis). That photographs or film can be (re)produced, the process provides us with the tools with which to think about the encounter between both photographs and the photographer, and photographs and the audience. More specifically to think about this encounter in terms of how it can provide a moment of self reflexivity and jar oneself out of one's normal state of being, to look anew at the world and the photographs. It is the aura which produces the jarring effect that makes this type of encounter possible (Hansen 2008).

A discussion of the aura in the context of photography raises the notion of trace, as found in Roland Barthes' Camera Lucida (1981), or Laura Marks' The Skin of the Film: Intercultural Cinema, Embodiment and the Senses (2000) who, referencing André Bazin, suggests that cinema's "fossil-like quality" is found in "the trace another material object leaves on the surface of the film" (93). However, there is an important difference between aura and trace, a distinction that can be found in Benjamin's The Arcades Project (1999), published posthumously. In it he wrote:

The trace is the appearance of a nearness, however far removed the thing that left it behind may be. The aura is the appearance of a distance, however close the thing that calls it forth. In the trace, we gain possession of the thing; in the aura, it takes possession of us (1999: 447).

While Picture of Light appears to be a study of the Northern Lights, it is really a study of media and knowledge. The trace (index) of the lights creates a sense 
of proximity for the viewer, an artifact of the past. However, the real focus here is the permeable boundary of index and object, and it is in this subtle distinction that the film is brilliant. By challenging the audience's notions of familiarity to the lights in the world and the lights in the film, the audience oscillates between observation and reflection, often through jarring juxtapositions. The aura is not found in the illuminations of the lights, or the characters on the screen; it is in the place where the audience questions their relationship to the film, the world it represents and the world they inhabit. The auratic experience resides in the film's affect, its “temporal disjunction, the shocklike confrontation of an alien self" (Hansen 2008: 350). Scenes like those of wind battering the microphone, or the ascending lines on the television screen jolt the audience out of passive and meditative states by emphasizing the presence of mediation to engage with the place of the film.

Ultimately, I argue that Picture of Light does contain an aura. It is not the aura of the Northern Lights, but the aura of the attempt to represent them on film. While the film provides the audience with an experience not unlike that which is represented, it is the construction of the film which becomes the audience's experience. While documentary film shares an amorphous contract with reality, I suggest here that Mettler has renegotiated what one expects to receive. It is not the trace of the lights as an "original" object, but the navigation of the documentation process. Mettler's narrative tells us more about place than any indexical reference does and it is in the construction of the film that the aura exists.

\section{Projecting Memory}

At one point in the film Mettler asks: "Are you cold yet?", as wind is made visible by the blowing ice crystals across the frozen tundra. Prior to the question, the narration had been discussing the story of the Lumière Brothers screening Train Arriving at a Station (1896), which caused audience members to jump out of their seats in terror as the image of the approaching train appeared as though it was going to continue through the screen. The narration continues: "We know what is by what is represented as much as what we have seen by ourselves." With the recounting of the Lumière Brothers story it appears that Mettler is mocking the limits of filmic portrayal, which a audience member might suspect is the purpose of the film, but with the follow up question he is, rather, suggesting the embodied memory of the audience. The audience's memory of ice and wind are brought into dialogue with the images and sounds of the film. ${ }^{9}$ Perhaps the key moment in the film, Mettler is suggesting that we advance our understanding of the world through engagements with mediation not unlike direct interactions in the physical world.

In their article "Knowledge and Memory: The Real Story" (1995) Roger Shank and Robert Ableson argue that stories constitute knowledge, memory and communication within society (1991: 1). 
Simply put, humans engage in two broad classes of actions involving language that depend upon knowledge. They try to comprehend what is going on around them and refer to what they already know in order to make sense of new input. And, they attempt to tell things to others, again referring to what they already know in order to do so. (Shank and Ableson 1995: 2)

Throughout the article Shank and Ableson demonstrate the concept of mapping. In the context of story-telling "[u]nderstanding, for a listener, means mapping the speaker's stories onto the listener's stories" (1995: 14). However, this also applies to interactions in the world apart from verbal communication. We interpret our experience of the world though our comprehension of how things work and function. Essentially, we connect our understanding of how we think the world works to our interactions, and it is at this juncture that we establish interpretations and create meaning in experience. It is from this understanding I suggest that Picture of Light is constructed such that it relies explicitly upon the manipulation of conventions to communicate its mastery of place. The place then becomes not only where the film was recorded or edited, but also the place of interaction with the audience.

Picture of Light is a film that synthesizes visual and aural elements to construct a representation of experience. The story the film tells is not of the Northern Lights, even though the index is there, but rather the story of mediation and its role in how we know the world. We forge meaning from the images and sounds by drawing upon our understandings of similar experiences. The film's identity is malleable and subjective, and while this could be said of all films its use of reflexivity to construct a narrative of place creates an aura that is independent of any purely indexical quality.

\section{Experiencing the Witness}

That film in general is an immersion in sound and light affords the ability to explore it through the notion of haptic space. In fact, the very materiality of film is based on haptics; translating touch into other sensory information. Light touches upon the film emulsion as the vibrations of air molecules touch upon the microphone. As opposed to the popular notion of the gaze (distanced), haptics (touch) provides a framework to investigate the personal qualities of film, blurring the border between objective and subjective experience. ${ }^{10}$ In the article "Women Recovering Our Clothes", Iris Marion Young (2005) writes, "[1]ess concerned with identifying things ... touch immerses the subject in fluid continuity with the object, and for the touching subject the object touched reciprocates the touching, blurring the border between self and other" (2005: 182). Further adding,

By touch I do mean that specific sense of skin on matter, fingers on texture. But I also mean an orientation to sensuality as such that includes all senses. 
Thus we might conceive a mode of vision, for example, that is less a gaze, distanced from and mastering its object, but an immersion in light and color. Sensing as touching is within, experiencing what touches it as ambiguous, continuous, but nevertheless differentiated. (Young 2005: 182)

While Young's article presents the author's thoughts on the collection and presentation of female clothing in the context of the gaze, looking at images of models in clothes she anticipates wearing, it is her exploration of transitioning between objectivity and subjectivity, in relation to experiencing, that I would like to draw upon for the purpose of this paper. Young is not looking upon the models in the magazine as separate from her, but suggests other ways that the images may be perceived (touch and bonding). This relates to The Skin of the Film... (2000), where Marks uses the notion of "haptic visuality" as a way to think about the perception of cinema as something less complete, less defined, and ultimately less distanced. Opposed to optical visuality, which "depends on a separation between the viewing subject and the object" (2000: 162), haptic visuality is less defined and complete, requiring an awareness to the physicality of the image to encourage modes of subjective interpretation. Both Young and Marks use haptics as a way to suggest that cinema can be can be thought of as more than a distanced experience. ${ }^{11}$

As I proposed earlier, when the audience sees the recording equipment in Picture of Light, there is a connection that is made both to the technologies as actors and how they operate as surrogates within the film. When the microphone is seen being redirected and the soundtrack reinforces this movement, the audience's placement within the film is temporarily crystallized. However, these scenes are fleeting and the audiovisual relationship is often established such that the connection encourages self-reflexion on the part of the audience. Jordan (2010) uses the idea of "immersive reflexivity" to describe this use in Picture of Light. He suggests that "conventions of sonic realism are contrasted with moments of lyricism and counterpoint that keep us aware of the artificiality of audiovisual relationships while pointing towards their inextricable links within the totality of the film" (2010: 193). He highlights a sequence of interviews with residents in Picture of Light as a key example of immersive reflexivity. The sequence begins with the synchronized voices and images of interviewees, but the connection of audio and visual fades in and out as some voices continue past their image. Subsequent images are replaced by yet other images of other interviewees while the voice of a previous subject remains. The oscillation between synchronized and non-synchronized sound highlights, for the audience, a position as separate from the subjects of the film. This positionality allows the audience to engage with the materiality of the film, emphasizing that image and sound are in fact separate and it is only in the mind of the audience that are they united.

Building from the perspective of the split relationship between the image and sound, Jordan suggests that Mettler's intentional use of sync and non-sync sound in Picture of Light functions as a reminder of the synthesis that takes place in film. 


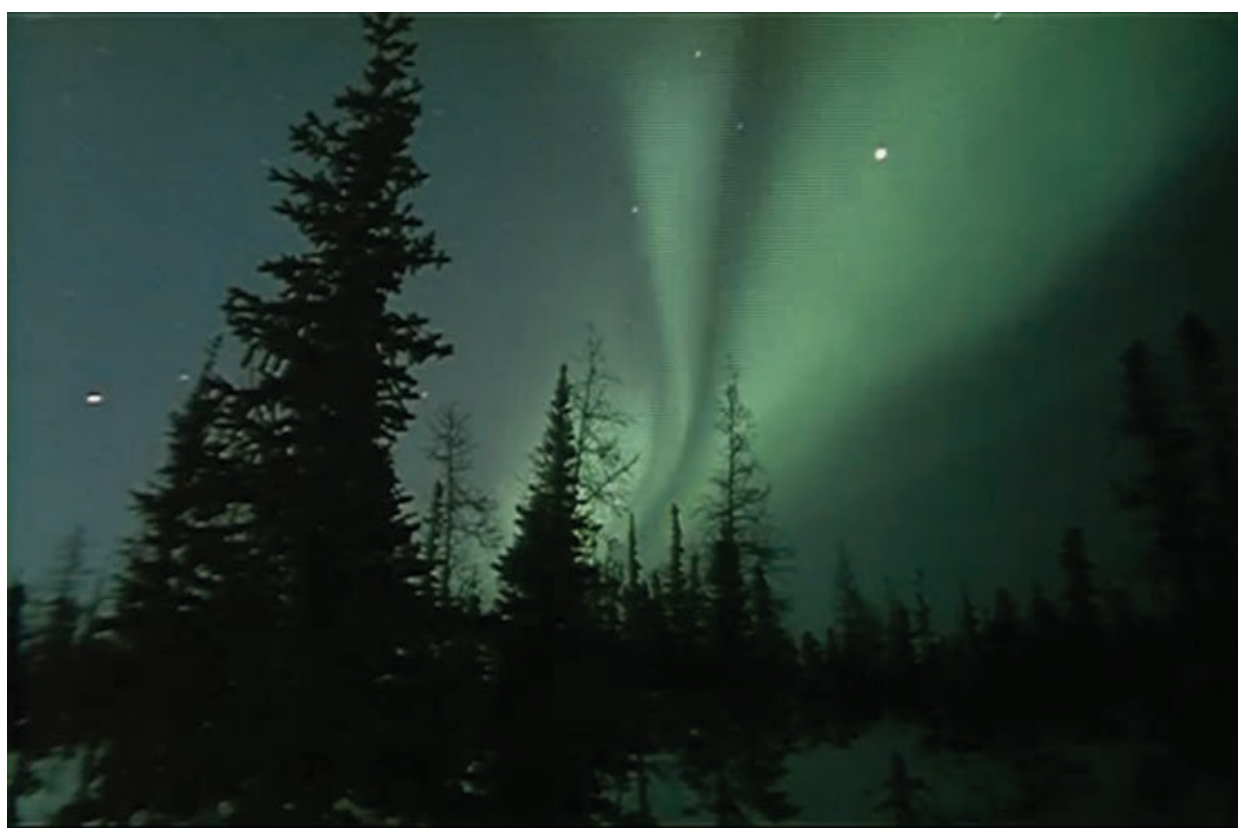

Figure 4. The silence of the lights exploits the audiovisual divide of cinematic representation by encouraging a connection with the audience's imagination

The image and the sound are only unified in the mind of the audience, so too is the experience presented in the film and the story it creates. Somewhat opposed to Brecht's distancing effect, where the audience is made aware of their position as removed from the actors in a play, immersive reflexivity emphasizes "a subjective experience of the split between sound and image that allows us to experience the world anew" (Jordan 2010: 231). For Jordan, the power of immersive reflexivity is that the silence of the lights in the film allows the audience to hear their own interpretation of the lights on the screen and it is this negation of space that highlights the haptic potential of Picture of Light (Jordan 2010).

So while immersive reflexivity works to bridge the gap between the internal and external, the point is that the audience is made aware of the distance to make sense of the immersion. As the division of image and sound allow space for the audience to participate with the narrative of the film, I suggest that it is also the use of the recording technologies that further encourages a place of engagement. Bourdieu's notion of the habitus helps to bring awareness to techniques of the performance. When we hear or see a technological device we experience the effect of the technology in the recording process. When we see the techniques used by the film crew we witness their attempt to represent experience, which shapes the film's narrative of place: its aura and its trace.

In the essay "Listening", from the book of the same title, philosopher Jean-Luc Nancy (2007) writes: 
To listen is to enter that spatiality by which, at the same time, I am penetrated, for it opens up in me as well as around me, and from me as well as toward me; it opens inside me as well as outside, and it is through such a double, quadruple, or sextuple opening that a "self" can take place." (Nancy 2007: 14)

This suggests that sound and listening both establish and dissolve the boundaries of the self simultaneously, making it dynamic and porous. What resonates in us is what is common to the self and the habitus which helps provide the right conditions for our disindividuation while still maintaining our alterity from the world. The essay is a contemplation of the relationship between knowledge and listening, suggesting that to hear something is to know it in a way that one would have knowledge of a subject through thought. This idea opens a discussion on the relationship between the individual and their surroundings, ultimately challenging the limits of knowledge, self and awareness. While Nancy is occupied with the primary experience of the individual in the physical world his thesis argues for an extension of phenomenological understanding, suggesting something of a resonance theory. It is our embodied self that resonates in sympathy to the vibrations surrounding it just as our actions produce vibrations of their own, which in turn cause other objects to resonate. ${ }^{12}$ This thought on sound provides a rich foundation for exploring the audiovisual representation of film as it relates to the perception of space within the film. The extension of the audience through the recording technologies, made present throughout the film, provides a source of feedback within the mediated context that encourages a sense of participation.

Both Nancy and Mettler question the relationship between knowledge and experience, as well as notions of interior and exterior. Picture of Light is a film that explores the possibility of experience through the limitations of representation. As the body is the site of knowledge where meaning is constructed, film can act upon the audience in a way not unique from how the non-technologically mediated world does. The audience brings forth their own understanding of the world into dialogue with the film the same way they would with any other experience. By foregrounding the technology and techniques of the crew, and the contemplative nature of the narration, the audience is asked to engage with the film with their embodied memory.

\section{Conclusion}

Picture of Light is about the experience of an attempt to represent the Northern Lights on film. By choosing something seemingly impossible, Mettler foregrounds the limitations of cinematic referent to create a narrative of place that in many ways is successful in moving beyond the original restrictions of the medium. The inclusion of both technique and technology create a place for the audience to engage and question. Likewise, the exploitation of the medium's qualities further creates a place for observation and self-reflexive awareness. By 
continually questioning the possibility of representing the lights in film and challenging what connection is, he produces the aura of an attempt to represent the lights on film, and it is that attempt which is most well preserved.

\section{Notes}

1 McSorley (1995) builds from the idea that Mettler's epistemological alliance falls around an "anti-Grierson worldview-[that]seeing isn't always believing" (1995: 42), the author looks at the directors approaches at representing that which "cannot be captured on film" (1995: 1).

2 Mettler (1992) discusses the idea that images can be presented to operate on an abstract level similar to that of music - this hints to the pre-symbolic ideology of experimental film.

3 See Chion (1994).

4 Jim O'Rourke, an American musician/producer composed the score for the film while Mettler processed many of the recorded sounds to obscure the reference between soundtrack and location.

5 Leading figure in American experimental film. Known for his affective, visceral use of the medium.

6 See McLuhan (1964).

7 For a more detailed account of technology and authenticity see Frith (1986).

8 Though not completely as Sterne (2003a) has demonstrated that there is no such thing as a "vanishing mediator" (285).

9 Schank and Ableson (1995: 18-19) discuss in detail the possibility of communicated understanding even though each person has their own unique collection of memories that are drawn upon to form interpretations of the current story being processed.

10 Sterne has demonstrated in his book The Audible Past (2003a), that there is an often held misconception that sound is associated with the interiority while vision the exteriority. In his book, he lists what he refers to as the "audio visual litany" (2003a: 15) which challenges many of the commonly held assumptions of vision and hearing that are related to objectivity and subjectivity, respectively. When thinking about sound alone, it is easy to think about how sound reflects the surface area of space, and how our movement in space informs us of our surroundings through acoustic feedback. This has been demonstrated in great detail by Blesser and Salter in their book Spaces Speak, are you listening? (2007).

11 While Young (2005) and Marks (2000) both write of the "gendered body", in the interest of space this paper treats the body of the "audience" as undifferentiated.

12 For detailed discussions on the listener as sound-maker see the writings of Westerkamp (1988; 2006), Truax (2001) and Czink (2013).

\section{Acknowledgements}

Thanks to Zoë Druick, Randolph Jordan, Matthew Hayes, Serena Thomson, Andrew Czink and the two anonymous reviewers for comments and suggestions throughout the development of this paper. I would also like to thank Peter Mettler and Grimthorpe Film Inc. for granting the permission to include images from Picture of Light in this paper. 


\section{References}

Atwood, Margaret (1987) “True North”. Saturday Night 141, 141-148.

Barthes, Roland (1981) Camera Lucida. New York: Hill and Wang.

Benjamin, Walter (1968) Illuminations: Essays and Reflections. New York: Schocken Books.

Benjamin, Walter (1983) "N [Theoretics of Knowledge; Theory of Progress]". In: Smith, Gary (ed.) Benjamin: Philosophy, Aesthetics, History. (Trans. of Passagen-Werk by Leigh Hafrey and Richard Sieburth). Chicago: Chicago University Press, 43-83.

Benjamin, Walter (1999) The Arcades Project. (Rolf Tiedemann, Ed., Trans. Howard Eiland and Kevin McLaughlin). Cambridge: Belknap Press.

Blesser, Barry and Linda Ruth Salter (2007) Spaces Speak, Are You Listening?: Experiencing Aural Architecture. Cambridge: MIT Press.

Bourdieu, Pierre (1990) The Logic of Practice. (Trans. Richard Nice). Stanford: Stanford University Press.

Brecht, Bertolt (1961) “On Chinese Acting”. The Tulane Drama Review 6 (1), 130-136.

Chion, Michel (1994) Audio-Vision. New York: Columbia University Press.

Czink, Andrew (2013) Sound Means: Towards an Epistemology of Auditory Experience... (Master's thesis). Retrieved 2013, from https://theses.lib.sfu.ca/thesis/etd8137.

Frith, Simon (1986) "Art Versus Technology: The Strange Case of Popular Music". Media, Culture, and Society 8, 263-279.

Grace, Sherrill E. (2002) Canada and the Idea of North. Montreal: McGill-Queen's University Press.

Hansen, Miriam B. (2008) "Benjamin's Aura”. Critical Inquiry 34 (2), 336-375.

Jordan, Randolph (2010) The Schizophonic Imagination: Audiovisual Ecology in the Cinema (Unpublished doctoral dissertation). Montreal: Concordia University.

Kittler, Friedrich (1999) Gramophone, Film, Typewriter. Redwood City: Stanford University Press.

Marks, Laura, U. (2000) The Skin of the Film: Intercultural Cinema, Embodiment and the Senses. Durham: Duke University Press.

McLuhan, Marshall (1964) Understanding Media; the Extensions of Man. New York: McGrawHill.

McSorley, Tom (1995) "Paradox and Wonder: the Cinema of Peter Mettler". Take One 7, Winter, 42-46.

Mettler, Peter (1992) "Music in Film: Film as Music". Cinemas: Revue d'Études Cinematographiques = Journal of Film Studies 3 (1), 34-42.

Mettler, Peter (1994) Picture of Light. 83 minutes. Grimthorpe Film.

Nancy, Jean Luc (2007) Listening. New York: Fordham University Press.

Schank, Roger and Robert Ableson (1995) "Knowledge and Memory: The Real Story". In: Wyer, Robert S., Jr. (ed.) Knowledge and Memory: The Real Story, Hillsdale: Lawrence Erlbaum Associates, $1-85$.

Shaviro, Steven (1993) Cinematic Body (Theory Out Of Bounds). Minneapolis: University of Minnesota Press.

Sterne, Jonathan (2003a) The Audible Past: Cultural Origins of Sound Reproduction. Durham: Duke University Press.

Sterne, Jonathan (2003b) "Bourdieu, Technique and Technology". Cultural Studies 17 (3-4), 367389.

Sterne, Jonathan (2006) “Communication as Technè". In: Shepard, Gregory J., Jeffrey St. John and Ted Striphas (eds.) Communication as... Perspectives on Theory. London: SAGE publications, 91-98.

Taylor, Charles (1991) The Malaise of Modernity. Toronto: House of Anansi Press.

Truax, Barry (2001) Acoustic Communication, $2^{\text {nd }}$ ed. New York: Ablex Publishing. 
Wees, William C. (1993) Recycled Images: The Art and Politics of Found Footage Film. New York: Anthology Film Archives.

Westerkamp, Hildegard (1988) Listening as Soundmaking: A Study of Music as Environment. Burnaby: Simon Fraser University.

Westerkamp, Hildegard (2006) Soundwalking as Ecological Practice. International Conference on Acoustic Ecology. Hirosaki: Hirosaki University.

Young, Iris Marion (2005) On Female Body Experience: "Throwing Like a Girl" and Other Essays. New York: Oxford University Press.

Nathan Clarkson has been participating in projects related to the preservation and management of the World Soundscape Project archives and other materials in the collections of the Sonic Research Studio at Simon Fraser University. As a graduate student in the School of Communication at SFU he is researching experimental audio practices with an interest in representation, identity, technique and technology.

Address: Nathan Clarkson, 7/1245 Bute Street, Vancouver, BC, Canada V6E 2A1. [email: nathanjamesc@gmail.com] 